\title{
Analysis of Pedestrian Facilities on MT Haryono Street at Malang City
}

\author{
D Ratnaningsih ${ }^{1}$ \\ \{dwi.ratnaningsih@polinema.ac.id $\left.{ }^{1}\right\}$
}

State Polytechnic of Malang, Jl. Soekarno Hatta No 9 PO BOX 4 Malang, East Java-Indonesia

\begin{abstract}
MT Haryono street is based on land use an educational area, because the road is near the Brawijaya University and State of Polytechnic Malang. The high number of pedestrians and traffic volume but not matched by pedestrian facilities has caused the performance of the road to be low. The purpose of this study was to analyze pedestrian facilities in MT. Haryono Street.This research uses quantitative analysis of pedestrian facilities. For analysis refers to the applicable minister of public works regulations.Based on the analysis results obtained by the number of pedestrians $=305$ people / hour, the number of pedestrians $=217$ people $/$ hour and the time between vehicles $(\mathrm{GAP})=2.99$ seconds, the recommendation for the selection of crossing facilities is Pelican cross on M.T Haryono Street
\end{abstract}

Keywords: Pedestrians, Pelican cross, the pedestrian Facilities, MT. Haryono street.

\section{Introduction}

Malang's predicate as a city of education is very appropriate, because most contributors to population growth in Malang City are students. The growth in the number of students in Malang City increases by an average of $5-10 \%$ per year (SuryaMalang.com).

This increase in traffic volume has received attention only on vehicle traffic infrastructure. While the need for infrastructure for pedestrians is still getting very little attention. Since pedestrians and pedestrians are a very important component of traffic, their safety is maintained, especially in urban areas. Pedestrians and pedestrians are usually concentrated in public facilities, such as terminals, shopping centers, education centers, and other public facilities. The presence of pedestrians requires adequate facilities, including crossing facilities such as the Crossing Bridge (JPO), Cross Zebra, Pelican Cross, and Tunnels.

The traffic on M.T Haryono street in Malang City during rush hour is quite dense but on the road it has not been matched by adequate pedestrian facilities. Pelican Cross's malfunction found on Jalan M.T Haryono, and the gap between vehicles that is too short often results in conflicts between pedestrians and vehicles, resulting in traffic delays, high accident rates and difficulty in pedestrians crossing the road. One of the objectives of this study is to find out what facilities are right for pedestrian crossers that are right on the MT Haryono street, in Malang City. 


\subsection{Definition of Road}

Road according to UU No. 22 of 2009 is divided into 4, namely: national roads, provincial roads, district roads, city roads, and village roads. City Road is a public road in a secondary road network system that connects service centers within the city, connects service centers with parcels, connects parties, and connects residential centers within the city.

The type of road on the city road is divided into 4, namely: two-way two-lane road (2/2 UD), two-way two-lane road (4/2 UD), divided two-way four-lane road (4/2 D), a divided two-way six lane road (6/2 D), and one-way road (1-3/1). Roads Parts of road between two vertices or intersections of a level or not in a plot of land either equipped with a traffic signal or not.

\subsection{Road Segments}

The length between and is not affected by signal intersections or intersections is not main signal, and has almost the same characteristics along the road. [1]

a. Traffic Conditions

Traffic conditions are determined according to the Planned Hourly Flow or Daily Average Traffic (LHRT) with factors suitable for LHRT conversion to hourly flows

b. Passenger Car Unit Factor

The factor for converting traffic flow of vehicles into equivalent flows in junior high school is for the purpose of capacity analysis.[2]

\subsection{Average Daily Traffic (LHR)}

The standard term is used in calculating traffic loads on a road segment and is the basis in the transportation planning process or in measuring pollution caused by traffic flow on a road segment LHR Formula:

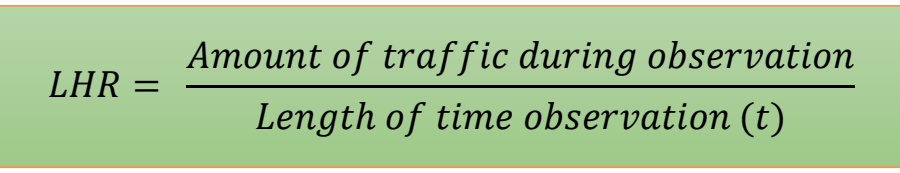

The headway calculated here is the time headway, which is the difference in time between vehicles passing one point in one lane. Time headways are used as a consideration for selecting crossing facilities where the smaller the time, the higher the capacity of the infrastructure.

\begin{tabular}{|l|l|l|}
\hline No. & Category & Time Headway \\
\hline 1. & High Density & $<2,5$ second \\
\hline 2. & Density & $2,5-9$ second \\
\hline 3. & Low Density & $>9$ second \\
\hline
\end{tabular}

Table 1. Flow Determination Criteria

(Source : Salter, RJ., 1997) 


\subsection{Pedestrians}

People walking on pedestrian tracks either on the roadside, sidewalks, special trails for pedestrians or crossing roads. To protect pedestrians in traffic, pedestrians must walk on the road and cross the crossing that has been provided for pedestrians.

The types of pedestrian facilities are as follows:

\section{a. Sidewalks}

Pedestrian pathways that are generally parallel to the road and higher than the surface of the pavement to ensure the safety of the pedestrian in question, the width of the sidewalk must be able to serve the existing pedestrian volume. The minimum width of the sidewalk is in accordance with the existing road classification.

b. Zebra Cross

Road crossings designated for pedestrians who will cross the road, are indicated by white and black longitudinal road markers with a thickness of $300 \mathrm{~mm}$ and with the same gap and a length of at least $2500 \mathrm{~mm}$.

c. Pelican Cross

Pedestrian crossings are controlled by traffic lights and are operated by pedestrians. Also equipped with zebra crossing (http://dishubkominfo.surakarta.go.id/kaktif/pelican-crosssing, accessed April 19, 2017 - At 16.12)

d. Crossing Bridge

Pedestrian facilities to cross a busy and wide road, so that people and vehicle traffic are physically separated. (http://id.wikipedia.org/wiki/J Jembatan_penyebrangan_orang, accessed April 20, 2017 - 09.19)

e. Crossing Terowong

Pedestrian facilities to cross roads that are built under or above the ground if there is a Cross Zebra, Pelican Cross, and Crossing Bridge that are not possible to use.

\subsection{Pedestrian Room Infrastructure Facilities}

The pedestrian space infrastructure facilities set forth in this guideline are pedestrian crossings. Effective pedestrian crossings are carried out through structuring various pedestrian elements, among others, information needed (pedestrian signs or instructions) that can be seen and accessed such as traffic signs, crossing signs (including crossings for pedestrians) who have physical limitations).

Correct crossings must be made by showing the right visibility or accessibility, traffic patterns in traffic stages, restrictions on turning right, duration or time that can be used by pedestrians, and safe measures of traffic that will allow pedestrians to cross. [3]

\subsection{Line Crossing}

a. Non-Regulatory Crossings (Zebra Cross)

Installed at the foot of the intersection without traffic signaling devices or on roads. The criteria for speed limits for motorized vehicles are $<40 \mathrm{~km} / \mathrm{hr}$.[4] 


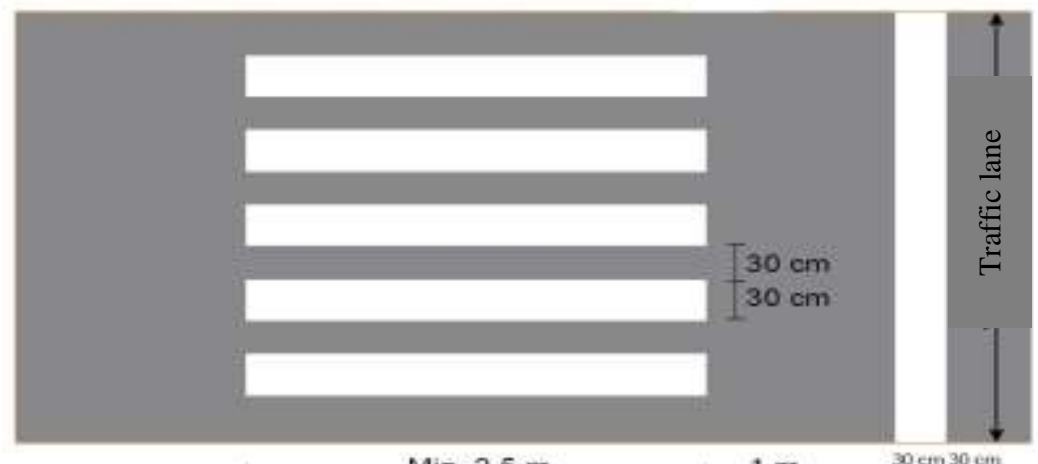

Min. $2,5 \mathrm{~m}$

$1 \mathrm{~m}$ $30 \mathrm{~cm}, 30 \mathrm{~cm}$

Figure 2.Crossing the Zebra Cross

(Source: Ministerial Regulation No. 34 of 2014 concerning Marka)

b. Crossing with Signal (Pelican Cross)

Mounted on roads, at least 300 meters from intersections, or on roads with average operational speed - vehicle traffic $>40 \mathrm{~km} /$ hour.[5]

\subsection{Crossings Not in the Field}

a. Bridge or Elevated

Bridge or elevated is used when:

1) Types of crossing lines cannot use zebra crossing.

2) The existence of pelican cross has disrupted existing vehicle traffic.

3) On roads with a high frequency of pedestrian accidents.

4) On roads that have high speed traffic flow and quite busy pedestrian flow.

b. Tunnel or Underground Or Underground tunnels are used when:

1) Types of crossing lines using bridges are not possible,

2) Location of land or terrain allows for tunnel construction.

The bases for determining the type of ferry facilities are as shown in Table 1 and Table 2 below:

\begin{tabular}{|l|l|l|l|}
\hline $\mathrm{pv}^{2}$ & $\mathrm{P}$ & $\mathrm{V}$ & Recommendation \\
\hline$>10^{2}$ & $50-1100$ & $300-500$ & Zebra crossing \\
\hline$>2 \times 10^{8}$ & $50-1100$ & $400-750$ & Zebra cross waiting stalls \\
\hline$>10^{8}$ & $50-1100$ & $>500$ & Pelican Cross \\
\hline$>10^{8}$ & $>1100$ & $>300$ & Pelican Cross \\
\hline$>2 \times 10^{8}$ & $50-1100$ & $>750$ & Pelican Cross waiting stalls \\
\hline
\end{tabular}




\begin{tabular}{|l|l|l|l|}
$>2 \times 10^{8}$ & $>1100$ & $>400$ & Pelican Cross waiting stalls \\
\hline
\end{tabular}

Table 1. Selection of based on PV2 Pedestrian Facilities

(Source: Pedestrian Facilities Technical Planning Module, 2014)

\section{Method}

Location of research / survey on the road Mayjend M.T. Haryono, Dinoyo, Malang City in front of the UB Faculty of Veterinary Medicine.

For more details, see the location map below:

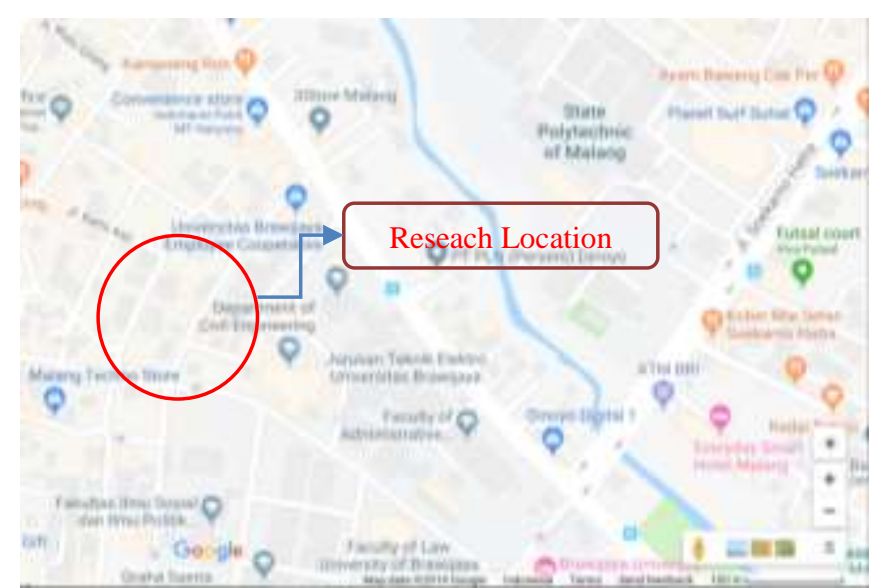

Figure 3. Research Location Map

(Source: goggle map.com)

\section{Result and Discussion}

The geometric data of the Jalan M.T Haryono section are as follows:

\subsection{Geometric Conditions and Road Facilities}

a. Road type: $2 / 2$ UD

b. Road segment length: 1900 meters

c. Total width: 10.5 meters

d. Road shoulder width: $<0.5$ meter (road shoulder only on one side)

e. Sidewalk width: 1.8 meters (sidewalks only on one side)

f. Median: there is no median

\subsection{Time Headway Data}

The method for determining the time between vehicles using the time headway. What is observed in light vehicles only. 


\begin{tabular}{|c|c|c|c|}
\hline No & $\begin{array}{c}\text { Times } \\
\text { (second) }\end{array}$ & No & $\begin{array}{c}\text { Times } \\
\text { (second) }\end{array}$ \\
\hline 1 & 2,45 & 27 & 2,59 \\
\hline 2 & 5,60 & 28 & 2,04 \\
\hline 3 & 6,29 & 29 & 3,32 \\
\hline 4 & 2,07 & 30 & 3,13 \\
\hline 5 & 1,41 & 31 & 0,95 \\
\hline 6 & 2,38 & 32 & 6,51 \\
\hline 7 & 3,48 & 33 & 4,03 \\
\hline 8 & 0,74 & 34 & 5,28 \\
\hline 9 & 2,38 & 35 & 6,41 \\
\hline 10 & 2,35 & 36 & 1,10 \\
\hline 11 & 2,48 & 37 & 3,05 \\
\hline 12 & 2,38 & 38 & 1,98 \\
\hline 13 & 3,38 & 39 & 3,84 \\
\hline 14 & 3,20 & 40 & 4,76 \\
\hline 15 & 1,94 & 41 & 3,48 \\
\hline 16 & 2,43 & 42 & 4,76 \\
\hline 17 & 1,62 & 43 & 3,48 \\
\hline 18 & 0,22 & 44 & 3,51 \\
\hline 19 & 2,19 & 45 & 2,54 \\
\hline 20 & 1,92 & 46 & 2,15 \\
\hline 21 & 1,52 & 47 & 3,11 \\
\hline 22 & 3,23 & 48 & 1,80 \\
\hline 23 & 4,76 & 49 & 1,67 \\
\hline 24 & 4,27 & 50 & 3,73 \\
\hline 25 & 3,68 & Total & 149,6 \\
\hline 26 & 2,00 & Average & 2,99 \\
\hline
\end{tabular}

Table 2 Inter-Vehicle Time Data (GAP)

(Source: Observation Results and Analysis)

From the data above, it can be seen that the time between vehicles (GAP) on Jalan M.T Haryono is 2.99 seconds. Indicates that on the road the time between vehicles is too short and makes pedestrians difficult to cross. It is recommended to plan a pedestrian bridge facility to make it easier for pedestrians to cross.

\subsection{Selection of Crossing Facilities}

From the side obstacle survey data, the data on the number of pedestrian crossings at peak hours is 522 people / hour (P). And the traffic volume from two directions is $2750 \mathrm{pcu} /$ hour (V). 


$$
p x v^{2}
$$

Information

p: Number of Pedestrians (person / hour)

v: Amount of Two-Way Traffic (vehicle / hour)

So that :

$$
522 \times 2750^{2}=3,94 \times 10^{9}
$$

Based on table 2.18 with a value of pv2 $=3.94 \times 109$. The recommended crossing facility is Pelican Cross with waiting stalls. But apart from the value of pv2, the selection of crossing facilities should consider aspects of safety and comfort for pedestrians. This is expected to make the crossers no longer have difficulties in crossing the Jalan M.T Haryono section.

\section{Conclusion}

The most appropriate pedestrian facility at this time to cross on the MT haryono road in Malang city is Pelicancross

\section{References}

$\mathbf{s}$ [1] Directorate General of Highways, "Procedures for Planning Bridges for Pedestrians in Cities." Jakarta, 1995.

[2] Directorate General of Highways, "Indonesian Road Capacity Manual (MKJI)." Jakarta, 1997.

[3] M. Ikbal, Muh., "Study of Pedestrian Characteristics and Selection of Types of Pedestrian Crossing Facilities in the City of Palu (Case Study: Jl. Emmi Saelan Front Taruta Mall, Palu City), Unpublished Journal. Palu." Civil Engineering Department of Tadulako University, 2011.

[4] Directorate General of Highways, "Guidelines, Provision, and Utilization of Pedestrian Network Infrastructure and Facilities in Urban Areas. (No.03 / PRT.M / 2014).” 2014.

[5] Regulation Minister of Transportation of the Republic of Indonesia, "Guidelines for Implementing Traffic Management and Engineering Activities. (Number PM 96 of 2015)." 2015. 
